\title{
Research on Cultivation Path of Tourism Entrepreneurship in Colleg- es and Universities
}

\author{
Baoshan Yang*
}

Beijing International Studies University, Beijing 100024, China. E-mail: 741560068@qq.com

\begin{abstract}
With the rapid development of tourism, new needs are put forward for the cultivation of tourism talents. The innovation and entrepreneurship education in local colleges and universities is the need for the survival and development of college students under the normal economic conditions, and it is also the requirement of the construction of innovative country and the comprehensive innovation of higher education in our country. This paper analyzes the present situation of tourism management professionals in applied colleges and universities in order to improve the training path of applied talents in tourism management majors in colleges and universities.
\end{abstract}

Keywords: Tourism Management; Applied Innovative Talents; Model Path

\section{Introduction}

Although the training of management professionals in colleges and universities has formulated relevant plans and has repeatedly emphasized the orientation of enterprise demand in the process, it can be seen from the results that the problem of mismatch between supply and demand is still very significant. It is difficult to combine theory and practice well, not to meet the changing market. Therefore, it is the key point to deal with the contradiction between tourism supply and tourism needs to establish a suitable orientation talent training purpose and to train the applied innovative entrepreneurial talents who can serve the regional economic development.

\section{Construction of innovative entrepreneurship training path}

\subsection{Pointing out the training goal of entrepreneurial talents}

According to the opinions on the reform and implementation of innovative entrepreneurial talents, the training objectives of entrepreneurial talents are as follows: cultivating innovative spirit and innovative thinking, cultivating innovative entrepreneurial consciousness, improving innovative entrepreneurial ability, and promoting the individualized development of students and the improvement of comprehensive quality. Innovative entrepreneurship education should not only cultivate students' innovative entrepreneurial skills, but also include the cultivation of innovative spirit, innovative entrepreneurial thinking and so on. Therefore, innovative entrepreneurship education should change from attaching importance to knowledge dissemination to potential development, combine knowledge imparting with ideological guidance, integrate theory teaching and skill training, and combine professional education with entrepreneurship education.

\subsection{Entrepreneurship education}

The training of entrepreneurial talents is manifested in the whole teaching process, and the following principles should be followed in carrying out the work.

\subsubsection{Classified teaching principles}

First, for all students to carry out general and sow the seeds of innovation and entrepreneurship in the hearts of students; second, combining different professional characteristics and industry development trends to guide students to Carry out innovation and entrepreneurship education according to professional knowledge and skills, leading students to

\footnotetext{
Copyright (C) 2021 Baoshan Yang

doi: 10.18686/mmf.v5i1.3276

This is an open-access article distributed under the terms of the Creative Commons Attribution Non-Commercial License (http://creativecommons.org/licenses/by-nc/4.0/), which permits unrestricted non-commercial use, distribution, and reproduction in any medium, provided the original work is properly cited.
} 
innovate, create and start a business according to knowledge and skills; third, for students with clear entrepreneurial goals, set up entrepreneurial ability promotion classes, entrepreneurship management education and entrepreneurship training, improve students' entrepreneurial opportunities.

\subsubsection{Integration principles}

The advantage of college students' independent entrepreneurship lies in their own professional knowledge and practical skills, so they can add the concept and thought of entrepreneurship education to professional education. Firstly, schools should take entrepreneurship education as the orientation and promote vocational education reform; secondly, entrepreneurship courses of different disciplines should be set up according to discipline development and social needs In addition, schools can carry out different types of entrepreneurship training, on the basis of professional teaching, expand the platform and space for the implementation of entrepreneurship education, and guide students to professional entrepreneurship.

\subsubsection{Practice guiding principles}

First of all, the curriculum should be set up with distinctive innovation and entrepreneurship courses based on world industrial technology revolution, regional economic development, industrial structure and the characteristics of the school. Secondly, according to the process of enterprise establishment, the school deals with practical problems from the perspective of college students who are engaged in Ampere innovation and entrepreneurship training courses. On the basis of entrepreneurship association, the school can organize students to carry out various entrepreneurship activities, such as entrepreneurship design competition and entrepreneurship experience forum, aiming at establishing a systematic learning practice for students ${ }^{[1]}$.

\section{Problems in the training of tourism talents in higher vocational colleges}

\subsection{Lack of high-quality personnel}

From the analysis of the current tourism market, the shortage of high-quality talents is a widely existing problem in various regions. At the same time, the problems of large turnover of personnel and high turnover rate need to be dealt with, and the existing tourism management majors in higher vocational colleges cannot meet the needs of the current market. What is needed in this era is comprehensive and professional talents, which requires students to master the theory of tourism service, service practice, management regulations, intelligent tourism technology and other knowledge. At present, most of the tourism courses in higher vocational colleges are concentrated in the category of specialized courses, such as tourism marketing, tourism practice knowledge and so on. If the talent training mode cannot catch up with the needs of the times, it will inevitably make the students unable to find a job after graduation.

\subsection{Talent innovation and entrepreneurship is not enough}

In any industry, innovation is the eternal driving force, tourism industry is not excluded. Entering the era of intelligent tourism, we must keep up with innovation in order not to be eliminated. At present, the market needs comprehensive talents with innovative ability and entrepreneurial ability, but the training of tourism entrepreneurial talents lags far behind the needs of the market, and professionals lack the ability of innovation and entrepreneurship. Although colleges and universities have invested a lot of energy in the cultivation of talents' practical ability, the teaching content has not kept pace with the times, and the students have few opportunities to participate in tourism entrepreneurship and cannot achieve the established purpose. And in the current cultivation mode, although many higher vocational colleges put talent innovation and entrepreneurship in your important position, the combination with entrepreneurial tourism talent is very low ${ }^{[2]}$.

\subsection{Single teaching method}

Tourism is a practical applied subject, which requires students to have strong knowledge processing and problem handling ability. Students' knowledge expansion ability is not excellent, which will directly lead to the lack of professional application ability. In the past, the theory teaching takes the teacher as the core, while inculcates the book knowledge to the students, inevitably causing the loss of students' enthusiasm. The student's creativity is very difficult to obtain the development. In the process of practical teaching, the teacher often uses his own operation demonstration, and then lets the students group simulation. After several demonstrations, such a single exercise will make the students tired and discount the effect of practical training. And with the development of network technology, students' access to information has been increasing. Now the post-90s and post-00 students need to teach teachers more and more. Many teachers suggest that pictures and videos that used to attract students' attention have gradually lost their appeal.

\subsection{Curriculum design needs improvement}


Nowadays, there are two kinds of applied undergraduate colleges and universities in our country: one is the traditional ordinary undergraduate college; the other is the promotion of higher vocational college to undergraduate course. The former emphasizes the system of knowledge structure in curriculum setting with less theoretical study and practical courses, and students cannot master tourism service skills well; the latter is disturbed by teaching ideas and focuses on practical links. Students are more likely to use corporate first-line service needs, but there is insufficient theoretical knowledge and limited room for rise.

\section{Training measures for entrepreneurial higher vocational tourism per- sonnel}

\subsection{Improving the construction level of teachers}

In the teaching team, we should implement the measures to go out and bring in. Full-time teachers are required to "go out" at least once every five years while in school. They need to enter the enterprise, through in-depth training, to understand the latest development of the industry and the latest technology of the enterprise, take the initiative to get familiar with the professional personnel of the enterprise, and ensure the speed of updating their knowledge. For high-level talents, flexible ways are used to introduce high-level disciplines and skilled personnel from industries and other colleges and universities, to give play to their professional skills and to promote the development of teachers ${ }^{[3]}$. In addition, we should set up a qualified teacher evaluation system, change the evaluation method of the previous scientific research index, and turn to the scientific research system, avoid the university teachers only focusing on individual scientific research projects, and despise the classroom teaching work. Schools are suggested to use different post classification management and evaluation requirements to mobilize teachers' enthusiasm. Finally, entrepreneurs and successful entrepreneurs who love entrepreneurship education are hired to undertake entrepreneurship guidance teachers and entrepreneurship lectures.

\subsection{Innovation and entrepreneurship optimization curriculum system}

The training of entrepreneurial tourism talents should be guided by the needs of talents in the era of entrepreneurial tourism. In addition to improving the traditional professional content, information courses should also be set up, including information technology, tourism professional content, network technology, so that they can master the technical ability and master the software and hardware operation. At the same time, the curriculum should highlight the specialty characteristics, strengthen the vocational quality education to provide a good environment for the cultivation of innovative entrepreneurial talents, and train students' ability of information acquisition, interpersonal communication and cooperation. In addition, we should innovate the practical teaching mode and carry out regular activities such as "Intelligent Tourism skills training week" and "Tourism Market Research" to let them feel the change of tourism mode in the tourism era. During the internship, let students contact tourists, practice skills in real positions, and bring themselves an extra income ${ }^{[4]}$.

\subsection{Optimizing teaching methods and realizing individualized teaching}

In the background of the Internet, the gap between the previous classroom teaching mode and the needs of students is gradually widening, and it has become a new situation for teachers to use the combination of traditional classroom and online classroom to carry out teaching activities. Teachers cannot only use micro-class, admiration class and other ways to stimulate students' exploration ability, but also can use QQ and other medias to communicate with students at any time, answer students' questions, and improve students' interest in learning. Students can also acquire their own interested knowledge from the network to achieve personalized teaching. And using the Internet, such as forums, some students remove their own concerns, actively put forward opinions and suggestions to teachers, through anonymous feedback from students, teachers can also be timely informed of the shortcomings of teaching, timely adjustment. It is helpful for teachers and students to interact and improve teaching efficiency and teaching effect.

\subsection{Integration Curriculum System}

In recent years, the development of tourism, cross-border blending has gradually become the norm, such as tourism education, tourism sports and so on. The curriculum design of tourism management major in colleges and universities is no longer simply limited to the introduction of tourism, traditional subjects of tour guide practice, and the contents of sports health exhibition planning and other content. In addition, for the short distance tourism market around the city, users have obviously changed in the way of reservation, which has been transferred from the PC end to the mobile phone, the mode of ordering offline experience with the mobile phone has become the mainstream, and the combination of tourism online and offline will become a reality. Industry insiders found that the current tourism management professional curriculum, can add e-commerce. Some courses such as tourism management information system can be added to some pure theoretical possibilities in order to keep up with the development of the industry. 


\subsection{Deepen School-Enterprise Cooperation}

Cooperation between schools and enterprises is the main way to cultivate applied and innovative talents in colleges and universities. Many colleges and universities have established internal and external training bases, but many bases are only superficial and do not play a real role. The cooperation between colleges and enterprises can realize the introduction of enterprise experts into the formulation of curriculum system. Only by joining the enterprises in the front line of the industry, their customized curriculum system is the knowledge that students need to master most. And the entrepreneurs will join the classroom teaching, they have a valuable case of the industry, after continuous teaching can inform the students of the latest information, so that students understand their own defects, purposeful improvement of their own skills. On the one hand, the school strengthens the cooperation with the practice base, so that the students can not only master the professional knowledge in the school, but also stabilize the professional skills outside the school, improve the vocational skills, and lay a good foundation for the graduating students. In addition, the school should use its own human advantages to help enterprises deal with the difficulties in development and promote the sustainable and stable development of enterprises. Therefore, the implementation of school-enterprise cooperation can not only improve the accuracy of college talent cultivation, but also a win-lose thing.

\subsection{Encourage students to engage in entrepreneurial activities}

In educational activities, students are given the opportunity to participate in innovative entrepreneurial practice. In the traditional tourism major teaching, although there are related contents but lack of systematic courses, all kinds of entrepreneurial projects can only stay on the surface. In order to improve students' entrepreneurial ability, we must take it as the main task, establish a social activity platform, and enrich the practical form of entrepreneurship. In order to achieve this goal, schools can encourage students to develop innovation and entrepreneurship independently, select suitable projects according to the current needs of tourism development, and provide technical and financial support to willing and capable students to build a better culture of innovation and entrepreneurship in schools. In addition, teachers should pay attention to the cultivation of students' awareness of innovation and entrepreneurship, start from the trend of the tourism market, assist students to find suitable projects, and encourage students to participate in different entrepreneurial competitions. Through multiple educational channels, entrepreneurial talents will be cultivated with deep theoretical knowledge and skilled operational skills, and they provide talent support for the establishment and development of intelligent tourism. Finally, the corresponding support platform has given for students' entrepreneurial activities. In the platform, students can obtain relevant information, watch micro-video, and communicate with teachers and students; after class, students can participate in innovative entrepreneurship competitions; in the activities, teachers provide students with full assistance and guidance, understand the problems encountered by students in innovative entrepreneurship, comment on their entrepreneurial plans and ideas, and help massage to improve themselves.

\section{The problems of cultivating entrepreneurial talents}

\subsection{Aims at entrepreneurship education}

Schools should take the cultivation of enterprising talents with pioneering personality as the main purpose of school teaching. In the establishment and development of entrepreneurial talents, we should grasp the needs of students' comprehensive, coordinated and sustainable development, cultivate and improve entrepreneurship, entrepreneurial psychology, entrepreneurial ability and entrepreneurial knowledge, and run qualities through the whole process of learning and education activities, as well as every link.

\subsection{Establish reasonable and effective teaching mechanism}

To realize the interaction of various teaching functions, we should publicize the concept and content of entrepreneurship in public basic courses and professional culture courses; whether it is an elective course or an academic report, it should be related to the content of entrepreneurship education. Whether campus activities, or student community organization activities, should be based on the cultivation of students' practical ability and innovation ability. Both school service and management should be people-oriented, with all the principles serving students.

\subsection{Implementing entrepreneurship training model}

The establishment of curriculum system should be based on the trend of combination of knowledge structure and science and culture. Therefore, it can be optimized from the following four points: first, increase the basic curriculum, humanistic literacy and scientific literacy education, so that students can learn from the wide memory. Second, increase the integration of literature and theory courses, so as to exercise students to use multi-disciplinary knowledge to deal with difficult problems from different angles. Fourth, give special lectures on entrepreneurship education courses to teach students entrepreneurial skills and knowledge, and exercise their management and management ability.

\subsection{Changing the training methods of tourism management and promoting Modern Management Forum




\section{KQIE linkage training mode}

Quality, knowledge and ability are the basic elements of becoming talents. These belong to transferable techniques, which cannot be acquired only by teaching students in class. Only by formulating the first classroom professional knowledge and the second classroom quality expansion activities can we realize. The third classroom focuses on cultivating students' innovative and entrepreneurial ability. The school promotes the improvement of students' project, the school promotes the improvement of students' actual innovation ability. The teacher enlightens the students' innovative ability through many times of paper transaction guidance. And the emergence of entrepreneurial platform, entrepreneurial center and incubator garden can enable students to experience the relationship between theory and practice in advance, realizing the learning mode of theory guiding practice and practical verification. Through the promotion of entrepreneurial ability, a bridge gradually established between theoretical knowledge and practical ability. It adds the purpose and need of the second class and the third class to the formula. In the first classroom, classroom teaching is carried out on the basis of the reform of the curriculum content of national tourism specialty. The carry out the linkage of the third classroom, lets the first classroom teaching content into the second classroom needs. The establishment of the first classroom system is aimed at the second classroom, satisfying the need of knowledge reserve, the targeted curriculum practice and cooperation, and strengthening of the development of experiments and other links.

\section{Conclusion}

The tourism management entrepreneurship talents trained in higher vocational colleges should be based on tourism vocational post skills and knowledge, set up a scientific and reasonable evaluation system, evaluate and assess students' entrepreneurial consciousness, entrepreneurial knowledge and entrepreneurial psychological quality development in different stages, and cultivate themselves into a high-quality entrepreneur with career spirit and pioneering spirit.

\section{References}

1. Chen S. A Study on the training path of innovative and entrepreneurial higher vocational tourism talents in the age of intelligent tourism (in Chinese). Teachers 2020; 419(08): $82-83$.

2. Cai J. Exploration of ways to integrate innovation and entrepreneurship education into the training of tourism management talents in higher vocational colleges (in Chinese). Industrial \& Science Tribune 2019; 18(08): 249 250.

3. Luo X, He Y, Tan H, et al. Research on the Training Path of Innovative and Entrepreneurial Talents in Local Colleges and Universities (in Chinese). Pioneering with Science \& Technology Monthly 2019; 32(05): 82 - 85.

4. Deng C. Research on the training path of entrepreneurial talents in independent college — taking Guangdong Ocean University Cunjin College as an example (in Chinese). Pioneering with Science \& Technology Monthly 2018; 31(10): 79-81. 